\section{А.В Морозова,}

И.В. Матыенко, Л.Н. Новикова

НИИ акушерства и гинекологии им. Д.О. Отта РАМН,

Санкт-Петербург

\section{ЧАСТОТА ИНФИЦИРОВАНИЯ И ЗАБОЛЕВАЕМОСТЬ ДЕТЕЙ ПРИ ВЫЯВЛЕНИИ УРЕАПЛАЗМ У МАТЕРЕЙ}

- Результаты исследования показали, что в последние годы увеличилась частота выявления Ureaplasma urealyticum у беременньх женщин и число тех из них, лечение которьх было не эффективным. В случае отсутствия эрадикации возбудителя у матери более чем у $20 \%$ новорожденньх детей при обследовании выявлялись уреаплазмы, среди них каждый пятый ребенок имел клинические проявления внутриутробной инфекщии (ВУИ). Однако следует подчеркнуть, что при реализации ВУИ у новорожденных, как правило, Ureaplasma urealyticum не является единственным этиологическим агентом, чаще всего отмечается сочетание с вирусами (шитомегаловирус, вирусы герпеса I, II типа), Chlamydia trachomatis, Streptococcus agalactiae, Candida albicans. Для решения вопроса о том, является ли наличие уреаплазм при отсутствии клинической картины заболевания транзиторным носительством возбудителя или это маркер латентной формы инфекции, требуется дальнейшее проспективное исследование роли Ureaplasma urealyticum в патологии детей раннего возраста.

- Ключевые слова: новорожденные; беременные женшины; Ureaplasma urealyticum
В последние годы отмечается увеличение числа беременных женщин, у которых выявляется Ureaplasma urealyticum, что определяет актуальность изучения роли этих микроорганизмов в формировании перинатальной патологии $[1,2]$. Данные литературы в отношении влияния Ureaplasma urealyticum на состояние новорожденных детей противоречивы. Одни исследователи относят Ureaplasma urealyticum к абсолютным патогенам, способным играть роль в развитии синдрома дыхательных расстройств, пневмонии и бронхолегочной дисплазии у недоношенных детей [1-3], а также вызывать генерализованный воспалительный процесс $[4,5]$. Высказывается предположение о возможном значении инфицирования уреаплазмами в развитии патологии мочевыделительной системы $[1,6]$ и в возникновении аутоиммунных заболеваний у детей более старшего возраста [1, 7]. Другие авторы относят Ureaplasma urealyticum $\mathrm{K}$ условно-патогенным микроорганизмам, не имеющим самостоятельного значения в развитии воспалительного процесса [8, 9]. До настоящего времени не изучены особенности постнатальной адаптации новорожденных детей, инфицированных уреаплазмами, и не решен вопрос о необходимости проведения этиотропной терапии.

Цель настоящего исследования - изучить заболеваемость и частоту инфицирования новорожденных детей, родившихся от матерей, у которых во время беременности были выявлены уреаплазмы в гениталиях.

\section{Материалы и методы}

Проведен анализ частоты инфицирования Ureaplasma urealyticum 5032-х беременных женшин, а также обследованы в паре 434 матери и ребенка, находившихся в НИИ АГ РАМН им. Д.О. Отта в 2000-2003 гг.

Bсе женщины были обследованы в разные сроки беременности в условиях женской консультации и/или НИИ АГ РАМН им. Д.О. Отта. Материалом для исследований служило отделяемое цервикального канала и/или влагалища. Для выявления Ureaplasma urealyticum использовали метод полимеразной цепной реакции и культуральный метод. Новорожденные дети от матерей, колонизированных Ureaplasma urealyticum, были обследованы в первые сутки после рождения. С помощью метода полимеразной цепной реакции у них исследовали отделяемое задней стенки глотки, конъюнктивы нижнего века, вульвы и мочу. Определение ДНК Ureaplasma urealyticum проводилось с помощью набора реагентов для ПЦР-анализа «Полимик-Ур» (Москва, Литех). Одновременно детей обследовали для выявления хламидий, микоплазм, цитомегаловируса, вирусов герпеса I и II типов, условно-патогенной микрофлоры. Сведения о результатах обследования женщин и их детей были получены из обменных карт, историй родов и историй развития новорожденных. 


\section{Результаты исследования}

Результаты исследований показали, что частота выявления Ureaplasma urealyticum у беременных женшин за последние три года возросла. Так, в 2001 году были инфицированы 146 $(8,9 \pm 0,7 \%)$ из $1650-x$ беременных, в $2002-$ $179(11,4 \pm 0,8 \%)$ из $1570-x$, в $2003-266$ $(14,7 \pm 0,8 \%)$ из 1812-ти (p<0,01). У $57,4 \%$ инфицированных Ureaplasma urealyticum беременных при обследовании материалов, полученных из гениталий, одновременно с Ureaplasma urealyticum была выявлена другая микрофлора. Сочетание Ureaplasma urealyticum c Mycoplasma hominis имело место в 7,9\% случаев, с Chlamydia trachomatis - в 0,5\%, с грамположительной микрофлорой (Streptococcus B, Streptococcus sp., Enterococcus sp., Corynebacterium sp., Staphylococcus $s p . и$ др.) - в $22,3 \%$, с грамотрицательной микрофлорой (E.coli, Klebsiella pneumoniae) в $3 \%$ случаев. Сочетание Ureaplasma urealyticum более чем с двумя видами условно-патогенных бактерий встречалось в $8,9 \%$ случаев.

В 202-х случаях проведено гистологическое исследование последа. При этом выявлены патологические изменения как при наличии у матери только уреаплазм, так и при сочетании Ureaplasma urealyticum с другими микроорганизмами (табл. 1). В последнем случае частота преждевременных родов была выше, чем у женщин, колонизированных только уреаплазмами:
$23,3 \pm 4,6 \%$ (у 20 из 86 обследованных женщин) против $6,1 \pm 2,4 \%$ (у 8 из 116 обследованных женщин) - p $<0,01$.

Далее мы попытались выяснить, какова частота инфицирования уреаплазмами новорожденных при колонизации гениталий матери Ureaplasma urealyticum. Оказалось, что из 434 детей, родившихся у матерей, половые пути которых были колонизированы уреаплазмами, у $80(18,4 \%)$ выявляли Ureaplasma urealyticum. Частота инфицирования ребенка уреаплазмами существенно не отличалась при наличии у матери только Ureaplasma urealyticum или при сочетании уреаплазм с другими микроорганизмами.

219 из 434 женшин (50,5\%) были пролечены в разные сроки беременности макролидами (эритромицин, ровамицин, вильпрафен, макропен) или получали местную терапию (свечи с доксициклином, свечи с эритромицином, свечи тержинан). Мы изучили частоту инфицирования новорожденных в зависимости от наличия и исходов лечения матерей. Установлено, что инфицированные уреаплазмами дети у женшин, получавших лечение, рождались в $14,6 \pm 2,4 \%$ (32 из 219), тогда как при отсутствии лечения - в $21,9 \pm 2,8 \%$ (47 из 215) случаев $(\mathrm{p}>0,05)$. Наличие или отсутствие лечения женшин сушественно не влияло на продолжительность беременности. Число доношенных детей составило соответственно $86,8 \pm 2,3 \%$

Таблица 1

Частота патологических изменений в последе у колонизированньх Ureaplasma urealyticum матерей

\begin{tabular}{|l|c|c|c|c|}
\hline \multicolumn{1}{|c|}{$\begin{array}{c}\text { Характер изменений/ } \\
\text { Возбудитель }\end{array}$} & $\begin{array}{c}\text { Хроническая } \\
\text { плацентарная } \\
\text { недостаточность (ХПН) }\end{array}$ & $\begin{array}{c}\text { Воспалительные } \\
\text { изменения }\end{array}$ & $\begin{array}{c}\text { Воспалительные } \\
\text { изменения + ХПн }\end{array}$ & $\begin{array}{c}\text { Без патологических } \\
\text { изменений }\end{array}$ \\
\hline $\begin{array}{l}\text { Tолько Ureaplasma urealyticum, } \\
\mathrm{N}=116\end{array}$ & $7(6 \%)$ & $48(41,3 \%)$ & $44(37,9 \%)$ & $17(14,7 \%)$ \\
\hline $\begin{array}{l}\text { Ureaplasma urealyticum + другая } \\
\text { микрофлора, } \mathrm{N}=86\end{array}$ & $6(6,9 \%)$ & $49(56,9 \%)$ & $19(22,1 \%)$ & $12(13,9 \%)$ \\
\hline
\end{tabular}

Таблица 2

Структура заболеваемости у инфицированных (А) и неинфицированньх (В) Ureaplasma urealyticum детей

\begin{tabular}{|l|c|c|c|}
\hline \multicolumn{1}{|c|}{ Группы/Заболевания } & $\mathrm{A}, \mathrm{N}=80$ & $\mathrm{~B}, \mathrm{~N}=354$ & $\mathrm{P}$ \\
\hline Внутриутробная инфекция & $12(23,5 \%)$ & $33(14,5 \%)$ & $<0,05$ \\
\hline Нарушение мозгового кровообращения I-II степени & $7(13,7 \%)$ & $36(15,7 \%)$ & $>0,05$ \\
\hline Задержка внутриутробного развития & $10(12,5 \%)$ & $54(15,2 \%$ & $>0,05$ \\
\hline Гемолитическая болезнь новорожденных & $2(3,9 \%)$ & $9(2,5 \%)$ & $>0,05$ \\
\hline Диабетическая фетопатия & $4(7,9 \%)$ & $29(12,7 \%)$ & $>0,05$ \\
\hline Врожденные пороки развития & $4(7,9 \%)$ & $12(3,4 \%)$ & $>0,05$ \\
\hline Синдром дыхательных расстройств & - & $8(2,2 \%)$ & \\
\hline Гипербилирубинемия неуточненной этиологии & - & $6(1,7 \%)$ & \\
\hline Недоношенность & $9(11,3 \%)$ & $35(15,3 \%)$ & $>0,05$ \\
\hline
\end{tabular}


(190 из 219) и $87,9 \pm 2,25 \%$ (189 из 215). Наметилась тенденция к возрастанию числа беременных, у которых после лечения не произошла эрадикация возбудителя (2001 г. $-46,7 \pm 12,9 \%$, 2002 г. $-51,6 \pm 8,9 \%, 2003$ г. $-70,3 \pm 7,5 \%$, $\mathrm{p}>0,05)$. При этом частота эрадикации уреаплазм не зависела от типа макролида или местной терапии. В случае эрадикации возбудителя только у 2 (5,9\%) из 34 женщин родились инфицированные уреаплазмами дети. В тех случаях, когда Ureaplasma urealyticum выявлялась и после лечения, инфицированные дети родились у $10(20,4 \%)$ из 49 матерей.

Анализ состояния 80 новорожденных, у которых при обследовании выявлялись Ureaplasma urealyticum, показал, что недоношенные дети среди них составляли $11,25 \%$ (9 из 80). Из всех детей, колонизированных Ureaplasma urealyticum, $51(63,8 \%)$ были здоровы, а у $29(36,2 \%)$ имелась перинатальная патология (табл. 2). Из таблицы видно, что в случае инфицирования ребенка Ureaplasma urealyticum внутриутробная инфекция наблюдалась чаще. Только у 4 из 12 новорожденных уреаплазмы явились единственным этиологическим агентом внутриутробной инфекции, при этом трое из четырех - недоношенные дети. В остальных случаях уреаплазмы выявлялись в сочетании с другими микроорганизмами, в частности, с цитомегаловирусом, вирусом герпеса II типа, Chlamydia trachomatis, Streptococcus agalactiae, Candida albicans.

\section{Обсуждение результатов и заключение}

В последние годы частота выявления уреаплазм у беременных женщин, по результатам нашего исследования, увеличилась с $8,9 \%$ до $14,7 \%$. Данные литературы в отношении колонизации урогенитального тракта беременных уреаплазмами противоречивы. Частота выявления этих микроорганизмов варьируется от 10 до $80 \%[1,3,5]$. Значительный разброс цифр, вероятно, обусловлен использованием различных методов лабораторной диагностики. Однако все авторы сходятся во мнении, что распространенность уреаплазменной инфекции в последнее время возросла [1-3]. Учитывая высокий процент сочетанной колонизации влагалища женшин уреаплазмами и другими микроорганизмами, не представляется возможным определить превалирующий фактор в развитии иммунопатологических реакций в тканях последа и организме ребенка. Однако одинаковая частота воспалительных и инволютивно-дистрофических изменений в последе как при наличии только уреаплазм, так и при сочетанной колонизации свидетельствует о возможности самостоятельного патогенного воздействия уреаплазм. По нашим данным, каждый пятый ребенок в случае колонизации уреаплазмами имел клинические признаки внутриутробной инфекции (ВУИ). Но следует подчеркнуть, что у доношенных детей в случае реализации ВУИ уреаплазмы, как правило, не являются единственным этиологическим фактором, чаще всего имеет место сочетание с вирусами (цитомегаловирус, вирус герпеса II типа), хламидиями, стрептококком группы В, грибами рода кандида. В случае выявления у новорожденных только уреаплазм в значительном проценте случаев не отмечалось никакой перинатальной патологии. Данные литературы свидетельствуют о более высокой частоте инфицирования новорожденных, которая достигает $45 \%$ [1], а также о большей значимости уреаплазм в развитии патологии новорожденных [1, 3]. Что касается лечения новорожденных, колонизированных Ureaplasma urealyticum, на данном этапе оно проводится лишь у тех, кто имеет клинические признаки заболевания. Для решения вопроса о том является ли колонизация уреаплазмами у новорожденных при отсутствии клинической картины заболевания транзиторным носительством возбудителя или это маркер латентной формы инфекции, требуется дальнейшее проспективное исследование роли Ureaplasma urealyticum в патологии детей раннего возраста.

\section{Литература}

1. Сидорова И.С., Черниенко И.Н. Внутриутробные инфекции: хламидиоз, микоплазмоз, герпес, цитомегалия // Рос. Вестн. перинатологии и педиатрии. 1998. - № 3. - C. 7-13.

2. Лаврова Д.Б., Гасанова Т.А., Михайлов А.В., Самсыгина Г.A. Частота распространения, диагностика и клиническое течение микоплазмоза у новорожденных // С6. тез. докл. Всероссийской Междисциплинарной научно-практической конференции. Саратов, 29-31 мая 2000. - С. 98-100.

3. Прилепская В.И., Абуд И.Ю. Урогенитальный микоплазм03 // Рус. Мед. Журн.. - 2002. - Т. 6., № 5. - С. 295-300

4. Мальцева Л.И. Роль микоплазм в развитии осложнений беременности и перинатальной патологии плода // Матер. Респуб. научно-практической конференции, Казань, 11 ноября 1999. - С. 35-42.

5. Башмакова М.А., Кошелева Н.Г., Калашникова Е.Л. Инфекция и бактериальная колонизация урогениталий у беременных, влияние на течение беременности, плод и новорожденного // Акуш. и гин. - 1995. - № 1. - С. 15-18

6. Малова И.О. Особенности уреаплазменной инфекции урогенитального тракта у девочек // Вестник дерматовенерологии. - 1999. - № 6. - С. 77-79.

7. Чернова О.А., Мальцева Л.И., Чернов В.М. Микоплазмы: молекулярные основы патогенности // Матер. Республ. научно-практической конференции, Казань, 11 ноября 1999. - C. $1-25$

8. Анкирская А.С., Демидова Е.М. Генитальный микоплазмоз как фактор риска развития акушерской 
и перинатальной патологии // Вестник академии мед. наук СCCP. - 1991. - № 6. - C. 21-25.

9. Ollicainen J., Rirppi M., Heiscanen-Kosmat, Heinanen K. Chronic lung disease of not associated with Ureaplasma urealyticum // Pediatr. Pulmonol. - 2002. - Vol. 32, N 4. P. 854-859.

\section{THE FREQUENCY OF DETECTION AND MORBIDITY IN CHILDREN BORN TO MOTHERS INFECTED WITH UREAPLASMAS}

\section{Morozova A.V., Matyenko I.V., Novikova L.N}

Summary: The result of our investigations have shown that the determination of Ureaplasma urealyticum infection among pregnant women has recently increased. There is an enlarge- ment of the number of women, who have got this infection after treatment. In this case more than $20 \%$ children have got Ureaplasma urealyticum and every fifth of them has clinical manifestation of intrauterine infection. But Ureaplasma urealyticum do not play important role in etiology of intrauterine infection. In most of cases $C M V$, Herpes I, II, Chlamydia trachomatis and Streptococcus $B$ where etiological reason. May be Ureaplasma urealyticum call out pathological immune reactions in placenta and in the organism of a child. In its turn it stimulates active colonization of other pathogens. Presently the treatment of children who have Ureaplasma urealyticum is carried out only if there is clinical realization of infection. The question about the treatment of latent forms of Ureaplasma urealyticum infection needs farthest investigations of the influence of Ureaplasma urealyticum in the health of children of early age.

Key words: newborn; pregnant women; Ureaplasma urealyticum 